\title{
Facilitation of sympathetic neurotransmission by phosphatidylinositol-4,5-bisphosphate-dependent regulation of KCNQ channels in rat mesenteric arteries
}

\author{
Yasuo Kansui, Kenichi Goto, Toshio Ohtsubo, Noboru Murakami, Kunihiko Ichishima, Kiyoshi Matsumura \\ and Takanari Kitazono
}

Sympathetic nerves regulate vascular tone by releasing neurotransmitters into the vasculature. We previously demonstrated that bradykinin facilitates sympathetic neurotransmission in rat mesenteric arteries. Although little is known about the intracellular mechanism modulating this neurotransmission, recent cell line experiments have shown that the KCNQ channel, which is inhibited by the depletion of membrane phosphatidylinositol-4,5-bisphosphate $\left(\mathrm{PIP}_{2}\right)$, participates in the control of neurotransmission by bradykinin. In the present study, we examined the mechanism regulating neurotransmitter release from rat perivascular sympathetic nerves. Excitatory junction potentials (EJPs) elicited by repetitive nerve stimulation $(1 \mathrm{~Hz}, 11 \mathrm{pulses,}$ $20 \mu \mathrm{s}, 20-50 \mathrm{~V}$ ), a measure of sympathetic purinergic neurotransmission, were recorded with a conventional microelectrode technique in rat mesenteric arteries. Bradykinin $\left(10^{-7} \mathrm{moll}^{-1}\right)$ significantly enhanced the amplitude of EJPs $(n=22, P<0.05)$. This enhancing effect was abolished by $\mathrm{N}$-type calcium-channel inhibition with $\omega$-conotoxin GVIA $\left(2 \times 10^{-9} \mathrm{~mol}^{-1}, n=8\right)$. The blockade of phospholipase $C$ with U-73122 $\left(10^{-6} \mathrm{molI}^{-1}, n=17\right)$ also eliminated the facilitatory effect of bradykinin. In addition, the effects of bradykinin were diminished by the prevention of $\mathrm{PIP}_{2}$ resynthesis with wortmannin $\left(10^{-5} \mathrm{~mol} \mathrm{I}^{-1} n=7\right)$ or KCNQ channel inhibition with XE-991 $\left(10^{-5} \mathrm{~mol} \mathrm{I}^{-1}, n=7\right)$. On the other hand, depletion of intracellular calcium stores with cyclopiazonic acid $\left(3 \times 10^{-6} \mathrm{moll}^{-1}, n=6\right)$ or the inhibition of protein kinase $C$ with bisindolylmaleimide-I $\left(10^{-6} \mathrm{moll}^{-1}, n=9\right)$ did not alter the action of bradykinin. These data demonstrate that the hydrolysis of $\mathrm{PIP}_{2}$ by phospholipase $\mathrm{C}$, which is activated by $G_{q / 11}$-coupled receptors, and subsequent $K C N Q$ channel inhibition enhance sympathetic purinergic neurotransmission presumably via the activation of $\mathrm{N}$-type calcium channels in rat mesenteric arteries.

Hypertension Research (2012) 35, 909-916; doi:10.1038/hr.2012.61; published online 17 May 2012

Keywords: excitatory junction potential; KCNQ channel; phosphatidylinositol-4, 5-bisphosphate; purinergic neurotransmission; rat mesenteric artery

\section{INTRODUCTION}

Arterial tone is regulated not only by endothelial cells but also by perivascular nerves. Stimulation of these perivascular nerves, including sympathetic, parasympathetic and sensory nerves, causes the release of various transmitters, such as norepinephrine, adenosine 5 -triphosphate (ATP), nitric oxide and calcitonin gene-related peptide (CGRP), to regulate vascular tone. ${ }^{1,2}$ Several substances, including kinins, have been reported to modulate the release of transmitters from perivascular nerves. ${ }^{3-5}$

Kinins are proinflammatory, vasoactive peptides that influence vascular relaxation via the release of endothelial mediators. Bradykinin also causes a pain response to tissue injury by acting on sensory neurons. ${ }^{6}$ We previously showed that bradykinin enhances purinergic neurotransmission by sympathetic nerves in rat mesenteric arteries. ${ }^{3}$ Additionally, the action of bradykinin was increased by captopril, an angiotensin-converting enzyme (ACE) inhibitor. ${ }^{3}$ Although the accumulation of bradykinin secondary to ACE inhibitor therapy may enhance endothelium-dependent relaxation in human arteries, ${ }^{7}$ our previous findings raised the possibility that bradykinin may partially counteract such a vasodilatory effect. Therefore, different aspects of bradykinin should be considered when ACE inhibitor therapy is considered, and it is important to elucidate the mechanisms that regulate the action of bradykinin. The facilitatory effect of bradykinin was mediated by bradykinin $B_{2}$ but not $B_{1}$ receptors; however, the subsequent intracellular mechanism was not clear, and neither nitric oxide nor prostaglandins were likely to be involved in the effect of bradykinin in that study. The kinin $B_{2}$ receptors belong to the G-protein-coupled receptor family, and it was recently shown that bradykinin acts on more than one $G$ protein in a neuronal cell line, although $B_{2}$ receptors are reported to be mainly coupled to $G_{q / 11} \cdot{ }^{8}$ 
Voltage-gated Kv7 (KCNQ) channels, underlying the M-type current, have been found throughout the peripheral and central nervous systems. ${ }^{9-12}$ The name of this M-current is derived from its suppression by muscarinic acetylcholine receptors in sympathetic neurons. The $\mathrm{M}$-current of neurons is a voltage-gated $\mathrm{K}^{+}$current that has a crucial role in regulating neuronal excitability, ${ }^{13,14}$ and the inhibition of KCNQ channels leads to membrane potential depolarization in neurons, which causes neural excitation. The open state of KCNQ channels is maintained by membrane phosphatidylinositol-4,5-bisphosphate $\left(\mathrm{PIP}_{2}\right)$; these channels are closed upon stimulation of receptors that induce $\mathrm{PIP}_{2}$ hydrolysis

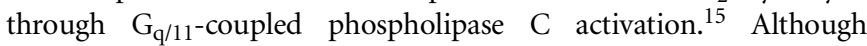
KCNQ channels are inhibited by muscarinic acetylcholine receptor stimulation, it has been suggested that angiotensin II and bradykinin

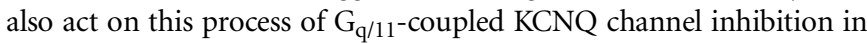
neurons. ${ }^{16-18}$ Thus, it is plausible to speculate that bradykinin facilitates sympathetic neurotransmission through its inhibitory effect on neural KCNQ channels.

In the present study, we evaluated bradykinin-induced sympathetic neurotransmission in blood vessels to elucidate the intracellular mechanism by which bradykinin modulates perivascular sympathetic nerves. We also showed that this neurotransmission was influenced by KCNQ channels. For this purpose, we recorded the excitatory junction potentials (EJPs), a measure of sympathetic purinergic neurotransmission, in rat mesenteric arteries using a conventional microelectrode technique.

\section{METHODS}

\section{Preparation of arteries}

This study was approved by the Animal Care Committee of Kyushu University. Six-eight-week-old male Wistar rats were killed by cervical dislocation. The second or third branches of the mesenteric arteries were excised and bathed in Krebs solution having the following composition (in $\mathrm{mmoll}^{-1}$ ): $\mathrm{NaCl} 121.8$, $\mathrm{KCl}$ 4.7, $\mathrm{MgCl}_{2}$ 1.2, $\mathrm{CaCl}_{2}$ 2.6, $\mathrm{NaHCO}_{3}$ 15.5, $\mathrm{KH}_{2} \mathrm{PO}_{4} 1.2$ and glucose 11.5.

\section{EJP recording}

The second or third branches of the mesenteric arteries were pinned out on a rubber base fixed at the bottom of the experimental chamber (capacity $2 \mathrm{ml}$ ). The chamber was superfused with Krebs solution at $36{ }^{\circ} \mathrm{C}$ aerated with $95 \%$ $\mathrm{O}_{2} / 5 \% \mathrm{CO}_{2}(\mathrm{pH} 7.2-7.3)$ at a rate of $3 \mathrm{ml} \mathrm{min}^{-1}$. After at least $60 \mathrm{~min}$ of equilibration, the membrane potentials of vascular smooth muscle cells were recorded using a conventional glass capillary microelectrode filled with $3 \mathrm{moll}^{-1} \mathrm{KCl}$ with a tip resistance of $50-80 \mathrm{M} \Omega$, as previously described. ${ }^{3,19}$ Criteria for successful impalement included the following: an abrupt drop in voltage upon impalement of the microelectrode into the vascular smooth muscle cell, a stable membrane potential for at least $2 \mathrm{~min}$ and a sharp return to zero potential upon withdrawal of the electrode. To record the EJPs, the periarterial nerves were stimulated by drawing the proximal part of the artery into a suction electrode $(\mathrm{Ag}-\mathrm{AgCl})$. An electric stimulator (SEN-3201, Nihon Kohden) was used to supply a train of pulses $(1 \mathrm{~Hz}, 11$ pulses, $20 \mu \mathrm{s}, 20-50 \mathrm{~V})$ every $2 \mathrm{~min}$. At this interval, the amplitudes of EJPs remained constant. Signals were amplified (VC-11, Nihon Kohden) and recorded (RJG-4002, Nihon Kohden).

\section{Drugs}

The following drugs were used: bradykinin $\left(10^{-7} \mathrm{moll}^{-1}\right),{ }^{3} \mathrm{U}-73122$ $\left(10^{-6} \mathrm{moll}^{-1}\right),{ }^{20} \mathrm{U}-73433\left(10^{-6} \mathrm{moll}^{-1}\right),{ }^{20}$ cyclopiazonic acid $\left(3 \times 10^{-6}\right.$ moll $\left.{ }^{-1}\right),{ }^{21}$ HC-030031 $\left(5 \times 10^{-6} \mathrm{moll}^{-1}\right),{ }^{22}$ H-89 $\left(10^{-6} \mathrm{moll}^{-1}\right),{ }^{8,23}$ XE-991 $\left(10^{-5} \mathrm{moll}^{-1}\right),{ }^{24}$ bisindolylmaleimide-I $\left(10^{-6} \mathrm{moll}^{-1}\right),{ }^{25}$ capsaicin $\left(10^{-5} \mathrm{moll}^{-1}\right),{ }^{26}$ capsazepine $\left(5 \times 10^{-6} \mathrm{moll}^{-1}\right)^{27}$ and phentolamine $\left(10^{-4} \mathrm{moll}^{-1}\right)^{28}$ from Sigma-Aldrich (St Louis, MO, USA) arachidonyl trifluoromethyl ketone $\left(3 \times 10^{-5} \mathrm{moll}^{-1}, \mathrm{AACOCF}_{3}\right)^{29}$ from Calbiochem (San Diego, CA, USA) $\omega$-conotoxin GVIA $\left(2 \times 10^{-9} \text { or } 10^{-6} \mathrm{moll}^{-1}\right)^{30,31}$ and Calcitonin Gene-Related Peptide (Human, 8-37) (CGRP8-37, $\left.10^{-7} \mathrm{moll}^{-1}\right)^{32}$ from Peptide Institute (Osaka, Japan) and wortmannin $\left(10^{-5} \mathrm{moll}^{-1}\right)^{33}$ and AP-18 $\left(10^{-6} \mathrm{moll}^{-1}\right)^{34}$ from Biomol (Plymouth Meeting, PA, USA). Stock solutions of bradykinin, phentolamine, $\omega$ conotoxin GVIA, H-89 and CGRP8-37 were dissolved in distilled water. Capsaicin was dissolved in ethanol. The other drugs were dissolved in $9.95 \%$ dimethylsulfoxide. If not otherwise specified, the inhibitors were added to the incubation solution, and the arteries were equilibrated for at least $20 \mathrm{~min}$ before obtaining responses. At their final chamber concentrations, the solvents used to dissolve the drugs did not affect electrical responses.

\section{Statistical analysis}

Data are expressed as means \pm SEM; $n$ refers to the number of animals examined. The values were accepted only when continuous recordings of EJPs were obtained throughout the application of bradykinin. The values of the peak effect of bradykinin were used for statistical analysis. Comparison of facilitatory curves of EJPs was performed by two-way analysis of variance (ANOVA). For additional reference, the area between the two facilitatory curves of EJPs was expressed in arbitrary units and was compared by one-way ANOVA followed by Dunnett's multiple comparison test. Other variables were analyzed by paired or unpaired Student's $t$-test. Values of $P<0.05$ were considered statistically significant.

\section{RESULTS}

The resting membrane potential of the rat mesenteric artery was $-70.4 \pm 0.8 \mathrm{mV}(n=36)$. The membrane potential in the presence of $10^{-7} \mathrm{moll}^{-1}$ bradykinin was $-69.3 \pm 1.2 \mathrm{mV}(n=18)$, which was not significantly different from the specimen without bradykinin treatment. Representative recordings of the effect of $10^{-7} \mathrm{moll}^{-1}$ bradykinin are shown in Figure 1a. Repetitive perivascular field stimulation facilitated the amplitude of EJPs with a maximal effect around 3-5 stimuli. Bradykinin significantly enhanced the amplitude of EJPs without affecting the resting membrane potential or the amplitude of the first EJP (Figure $1 \mathrm{~b}, n=22$ ). In subsequent experiments, the resting membrane potential and the amplitude of the first EJP were not altered by bradykinin except when otherwise stated. In addition, because bradykinin showed tachyphylaxis regarding its effect on EJPs, becoming weaker or absent upon the second application (data not shown), repeated use of bradykinin for the same arterial segment was avoided in the present study. Pretreatment with $10^{-6} \mathrm{moll}^{-1} \omega$-conotoxin GVIA, an N-type calcium-channel inhibitor, ${ }^{30,31}$ substantially decreased the amplitude of EJPs, and bradykinin no longer increased the amplitude of EJPs (Figure 1c, $n=4)$. When a low dose of $\omega$-conotoxin GVIA $\left(2 \times 10^{-9} \mathrm{moll}^{-1}\right)$, which mildly inhibits EJP amplitude, was added, a substantial EJP amplitude was still observed. Under this condition, the enhancing effect of bradykinin remained absent (Figures $1 \mathrm{~d}$ and $2 \mathrm{e}, n=8$ ).

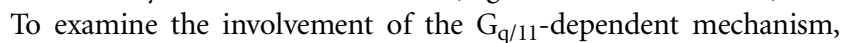
arteries were treated with $\mathrm{U}-73122\left(10^{-6} \mathrm{moll}^{-1}\right)$, a phospholipase $\mathrm{C}$ inhibitor. $^{20}$ The enhancing effect of bradykinin was substantially inhibited in the presence of U-73122 (Figures 2a and e, $n=17$ ). $\mathrm{U}-73433\left(10^{-6} \mathrm{moll}^{-1}\right)$, a negative analog of U-73122, ${ }^{20}$ showed no effect (Figures $2 \mathrm{~b}$ and e, $n=8$ ). On the other hand, inhibition of protein kinase $A$ or phospholipase $A_{2}$ with $\mathrm{H}-89\left(10^{-6} \mathrm{moll}^{-1}\right.$, $n=5)^{8,23}$ or $\mathrm{AACOCF}_{3}\left(3 \times 10^{-5} \mathrm{moll}^{-1}, n=8\right),{ }^{29}$ respectively, did not alter the effects of bradykinin (Figures $2 c-e$ ).

The activation of phospholipase $\mathrm{C}$, which is activated by bradykinin, degrades $\mathrm{PIP}_{2}$ to produce intracellular molecules. To explore the possible involvement of these substances in the effect of bradykinin, we tested the effect of wortmannin, which inhibits resynthesis of $\mathrm{PIP}_{2}{ }^{33}$ and XE-991, a KCNQ channel inhibitor. ${ }^{24}$ Wortmannin $\left(10^{-5} \mathrm{moll}^{-1}\right)$ and XE-991 $\left(10^{-5} \mathrm{moll}^{-1}\right)$ mildly depolarized the 

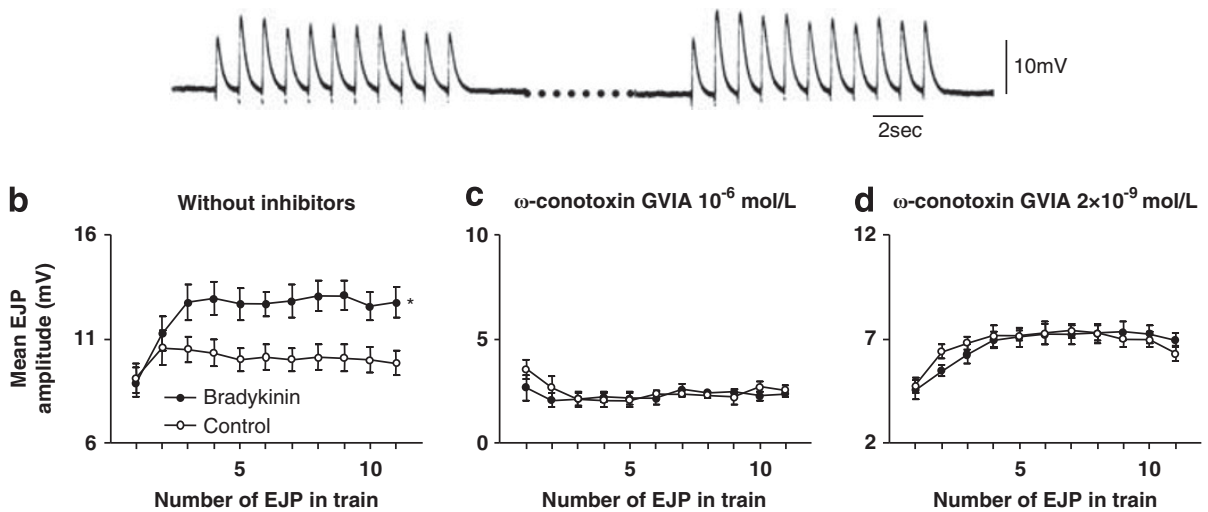

Figure 1 Effects of bradykinin on EJPs elicited by repetitive nerve stimulation in the rat mesenteric artery. (a) Representative tracings before and after application of $10^{-7} \mathrm{moll}^{-1}$ bradykinin. (b-d) Line graphs showing the effect of $10^{-7}$ moll ${ }^{-1}$ bradykinin on EJPs in the absence of inhibitors (b), or in the presence of $10^{-6} \mathrm{molI}^{-1}$ (c) or $2 \times 10^{-9} \mathrm{moll}^{-1}$ (d) $\omega$-conotoxin GVIA, an N-type calcium channel inhibitor. ${ }^{*} P<0.05$ vs. control by two-way ANOVA.

resting membrane potential of vascular smooth muscle cells (control $-67.4 \pm 1.0 \mathrm{mV}$, with wortmannin $-59.9 \pm 1.0 \mathrm{mV}, n=9, P<0.05$ control $-66.2 \pm 1.9 \mathrm{mV}$, with XE-991 $-61.1 \pm 1.4 \mathrm{mV}, n=15, P<0.05$ ). In the presence of wortmannin, the effect of bradykinin on EJPs was abolished without affecting the resting membrane potential (Figures 3a and e, $n=7)$. In addition, XE-991 also significantly reduced the facilitation by bradykinin (Figures $3 \mathrm{~b}$ and e, $n=11$ ). In contrast, neither cyclopiazonic acid $\left(3 \times 10^{-6} \mathrm{moll}^{-1}, n=6\right)$, a sarcoendoplasmic reticulum calcium ATPase inhibitor, ${ }^{21}$ nor bisindolylmaleimide-I $\left(10^{-6} \mathrm{moll}^{-1}, n=9\right)$, a protein kinase $\mathrm{C}$ inhibitor, ${ }^{25}$ altered the action of bradykinin (Figure 3c-e).

Neither capsaicin $\left(10^{-5} \mathrm{moll}^{-1}, n=8\right)$, which acts on sensory nerve terminals to release and ultimately deplete neuropeptides, ${ }^{26}$ nor CGRP8-37 $\left(10^{-7} \mathrm{moll}^{-1}, n=11\right)$, a CGRP antagonist, ${ }^{32}$ altered the effect of bradykinin (Figures $4 \mathrm{a}, \mathrm{b}$ and $\mathrm{g}$ ). Similarly, in the presence of AP-18 $\left(10^{-6} \mathrm{moll}^{-1}, n=4\right)^{34}$ or HC-030031 $\left(5 \times 10^{-6} \mathrm{moll}^{-1}\right.$, $n=12),{ }^{22}$ both of which inhibit transient receptor potential ankyrin 1 (TRPA1), the amplitude of EJPs facilitated by bradykinin was not altered (Figures $4 \mathrm{c}$, d and g). Capsazepine $\left(5 \times 10^{-6} \mathrm{moll}^{-1}, n=8\right)$, a transient receptor potential vanilloid 1 (TRPV1) antagonist, ${ }^{27}$ also did not affect the action of bradykinin (Figures $4 \mathrm{e}$ and g). In addition, in the presence of phentolamine $\left(10^{-4} \mathrm{moll}^{-1}, n=10\right)$, exogenously applied bradykinin continued to enhance the amplitude of EJPs (Figures $4 \mathrm{f}$ and $\mathrm{g}$ ).

\section{DISCUSSION}

The present study has demonstrated that the inhibition of KCNQ channels via depletion of $\mathrm{PIP}_{2}$ by phospholipase $\mathrm{C}$ activation contributes to enhanced sympathetic neurotransmission of bradykinin in rat mesenteric arteries. In addition, this enhancing effect of bradykinin is likely to depend on the activation of $\mathrm{N}$-type calcium channels. On the other hand, the downstream metabolites of phospholipase $\mathrm{C}$ might not be involved in the effect of bradykinin because neither the sarcoendoplasmic reticulum calcium ATPase inhibitor nor the protein kinase $\mathrm{C}$ inhibitor had any effect on the amplitude of EJPs facilitated by bradykinin. This is the first study to show that KCNQ channels have a key role in purinergic sympathetic neurotransmission in rat mesenteric arteries.

In our previous studies, we demonstrated that EJPs observed in rat mesenteric arteries are mediated by ATP but not by norepinephrine, ${ }^{31}$ although several studies have shown that ATP and norepinephrine are released from sympathetic nerves simultaneously. ${ }^{35,36}$ Therefore, it should be mentioned that EJPs recorded in the present study were mediated by purinergic sympathetic neurotransmission.

Bradykinin did not alter the first EJP in a train of repetitive nerve stimulations, nor did it alter the resting membrane potential after incubation with inhibitors shown to regulate intracellular mechanisms, in the present study; however, bradykinin continued to facilitate subsequent EJPs. Furthermore, in our previous study, bradykinin did not affect the magnitude of depolarization by $\alpha, \beta$-methylene ATP, a stable analog of ATP. ${ }^{3}$ These findings indicate that bradykinin may not directly affect the postsynaptic smooth muscle membrane or the responsiveness of myocytes to the transmitter responsible for EJPs in the study. Collectively, bradykinin probably facilitated the amplitude of EJPs by affecting presynaptic nerve endings around the rat mesenteric artery and not the postsynaptic smooth muscle membrane.

Norepinephrine released from nerve endings in response to nerve stimulation is known to inhibit the release of neurotransmitters via $\alpha_{2}$ adrenoceptors in presynaptic nerve terminals. ${ }^{37,38}$ Indeed, when phentolamine was used to inhibit adrenergic $\alpha$-receptors, the facilitation of EJPs was enhanced in the absence of bradykinin (data not shown). However, in arteries treated with phentolamine, bradykinin still showed a facilitatory effect on EJPs, suggesting that the action of bradykinin was unrelated to presynaptic $\alpha_{2}$-autoinhibition of neurotransmitter release.

Bradykinin binds to bradykinin $B_{1}$ or $B_{2}$ receptors. ${ }^{6}$ The $B_{1}$ receptors are expressed as a result of tissue injury and presumably have a role in inflammation. ${ }^{6}$ By contrast, it has been demonstrated that $B_{2}$ receptors are constitutively expressed and participate in the physiologic effects of kinins. ${ }^{6,39}$ We previously showed that bradykinin facilitates purinergic sympathetic neurotransmission in rat mesenteric arteries. In addition, this effect of bradykinin was mediated by presynaptic $B_{2}$ but not $B_{1}$ receptors. ${ }^{3}$ The $B_{2}$ receptors are G-protein-coupled receptors and are mainly described as coupled with $\mathrm{G}_{\mathrm{q} / 11},{ }^{40,41}$ although this receptor interacts with other $\mathrm{G}$ proteins, namely $\mathrm{G}_{\mathrm{s}}$ and $\mathrm{G}_{\mathrm{i}} \cdot{ }^{4-44}$ In the present study, the blockade of phospholipase $\mathrm{C}$, which is activated by $\mathrm{G}_{\mathrm{q} / 11}$, substantially diminished the action of bradykinin. Meanwhile, pretreatment with $\mathrm{H}-89$ or $\mathrm{AACOCF}_{3}$ to inhibit the $\mathrm{G}_{\mathrm{s}}$-cAMP-protein kinase A pathway or $\mathrm{G}_{\mathrm{i}}$-dependent phospholipase $\mathrm{A} 2$ activation, respectively, did not alter the effect of bradykinin. These findings suggest that in rat perivascular sympathetic nerves, the enhancing effect of bradykinin is probably mediated by $\mathrm{G}_{\mathrm{q} / 11}$, but not $\mathrm{G}_{\mathrm{i}}$ or $\mathrm{G}_{\mathrm{s}}$. 


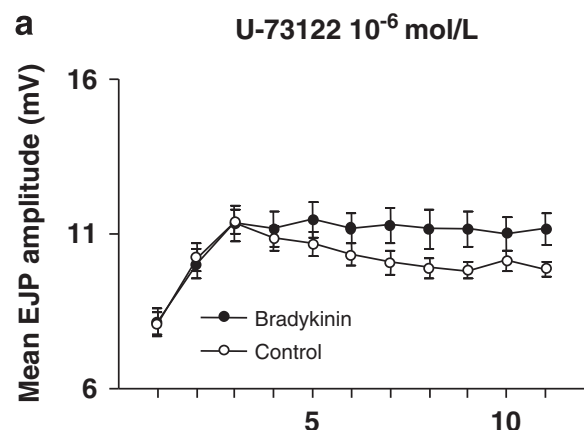

Number of EJP in train

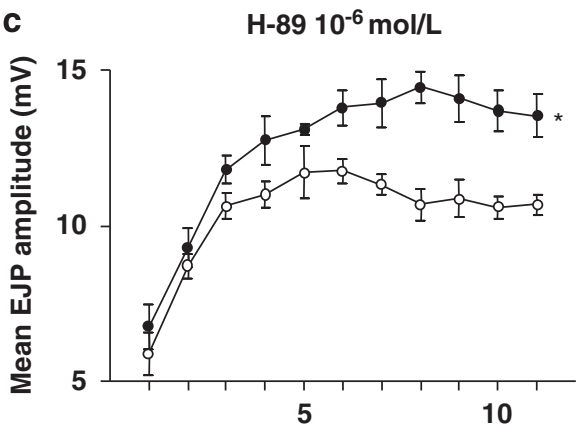

Number of EJP in train

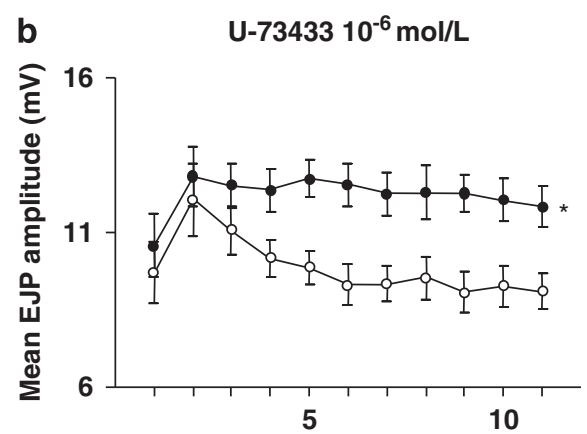

Number of EJP in train

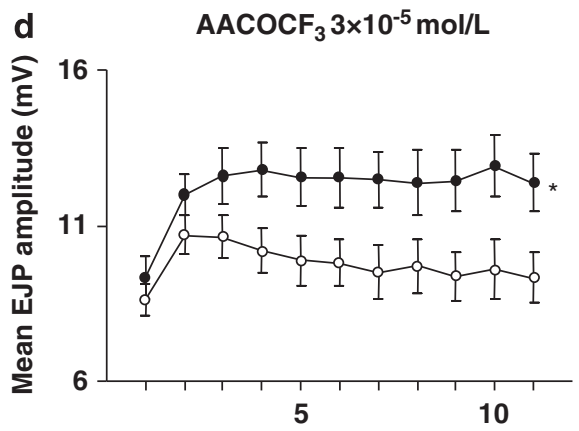

Number of EJP in train

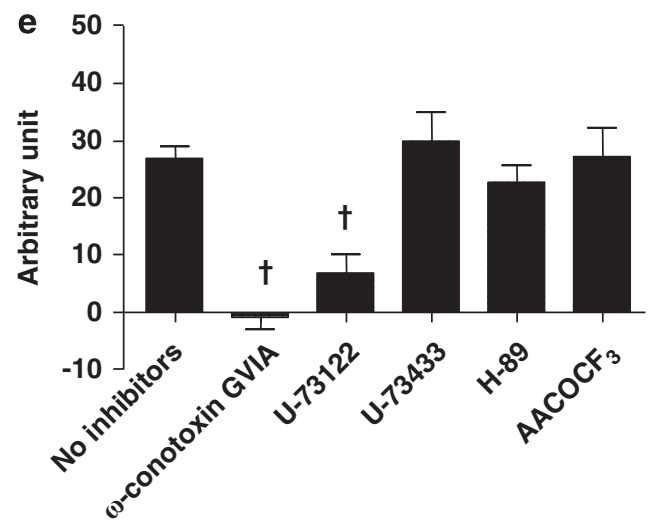

Figure 2 Line graphs showing the effects of $10^{-7}$ moll-1 bradykinin on EJPs in the rat mesenteric artery in the presence of the following: U-73122, a phospholipase C inhibitor (a); U-73433, a negative analog of U-73122 (b); H-89, a protein kinase A inhibitor (c); and AACOCF 3 , a phospholipase A2 inhibitor (d). (e) Bar graph showing bradykinin-dependent response (the area between two facilitatory curves of EJPs in each graph from Figures 1 and 2 , expressed as arbitrary units) in the presence of each inhibitor. ${ }^{*} P<0.05$ vs. control by two-way ANOVA. ${ }^{\dagger} P<0.05$ vs. no inhibitors by one-way ANOVA followed by Dunnett's multiple comparison test.

Activation of bradykinin receptors coupled to $\mathrm{G}_{\mathrm{q} / 11}$ leads to activation of phospholipase $\mathrm{C}$ to metabolize $\mathrm{PIP}_{2}$. It has been shown that $\mathrm{PIP}_{2}$ activates KCNQ channels in cell line studies and that depletion of $\mathrm{PIP}_{2}$ with a high concentration of wortmannin or the activation of phospholipase C inhibits KCNQ channel activity, which may cause neuronal depolarization. ${ }^{45}$ To elucidate the involvement of KCNQ channels in the present study, a high dose of wortmannin $\left(10^{-5}\right.$ moll $\left.{ }^{-1}\right)$ was employed to deplete $\mathrm{PIP}_{2}$ in the perivascular sympathetic nerves, resulting in the abolition of bradykinin-induced EJP facilitation. Furthermore, the prevention of KCNQ channel activity with XE-991 also substantially inhibited the enhancing effect of bradykinin. These findings support the involvement of
KCNQ channels in the facilitatory effect of bradykinin in rat perivascular sympathetic nerve activity.

KCNQ channels have increasingly been demonstrated to have an important role in arterial function. In vascular smooth muscle cells, KCNQ1, KCNQ4 and KCNQ5 are predominantly expressed with a minimal contribution of KCNQ2 and KCNQ3. ${ }^{46-48}$ In addition, Jepps et al. ${ }^{49}$ recently demonstrated that KCNQ channel activators induce arterial relaxation, and the expression of KCNQ4 is decreased in the vascular smooth muscle cells of hypertensive rodent models. The present study also suggested that perivascular sympathetic neurotransmission might also be influenced by KCNQ channels in rat mesenteric arteries. Thus, it appears that multiple action sites of 
a

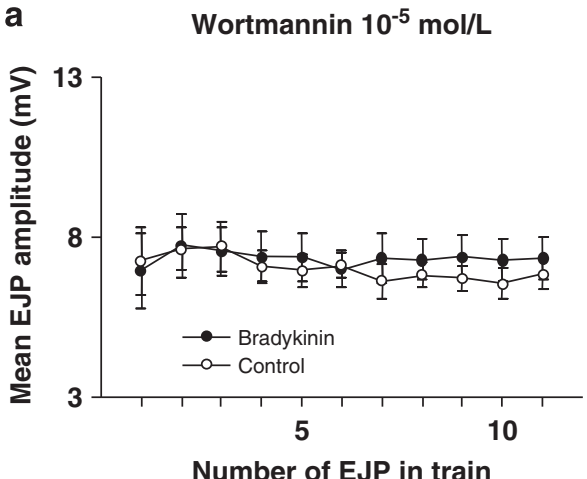

C

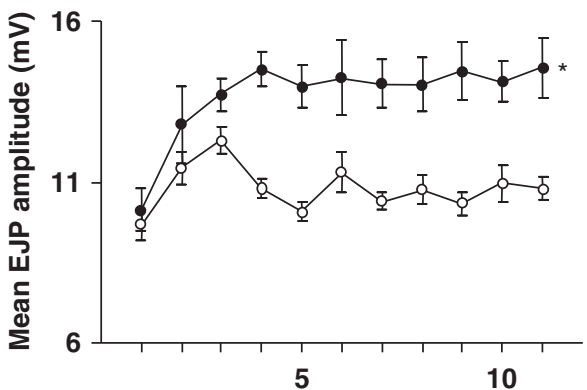

Number of EJP in train b

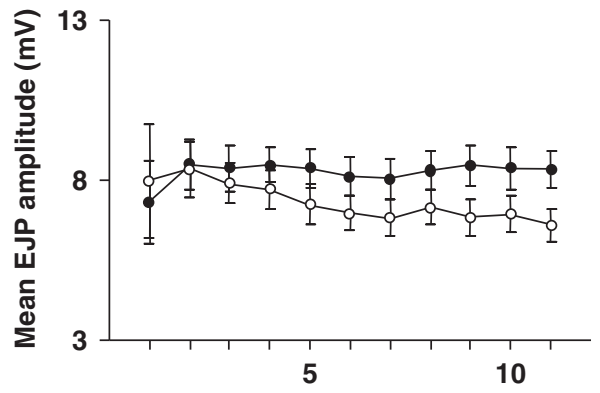

Number of EJP in train

d Bisindolylmaleimide- $3 \times 10^{-6} \mathrm{~mol} / \mathrm{L}$

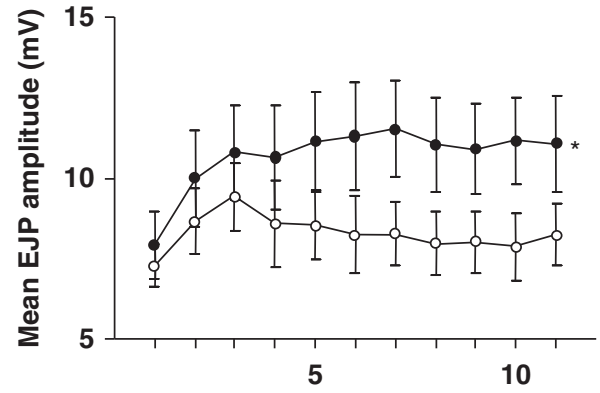

Number of EJP in train

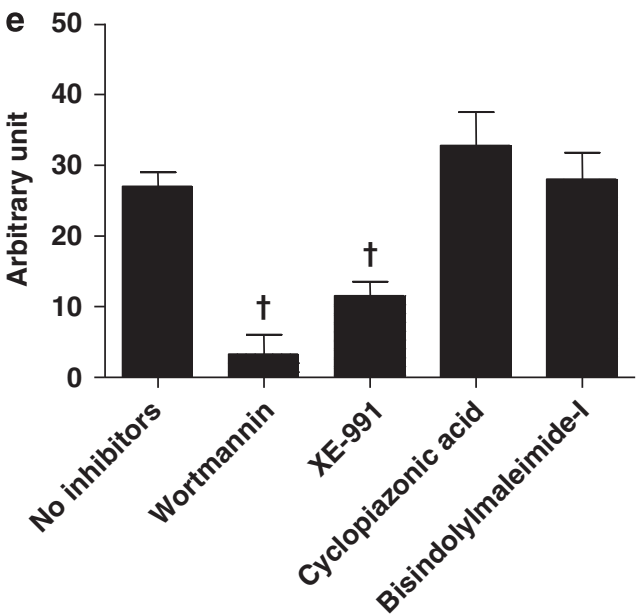

Figure 3 Line graphs showing the effects of $10^{-7} \mathrm{moll}^{-1}$ bradykinin on EJP in the rat mesenteric artery in the presence of the following: wortmannin, a resynthesis inhibitor of phosphatidylinositol-4,5-phosphate (a); XE-991, a KCNQ channel inhibitor (b); cyclopiazonic acid, a sarcoendoplasmic reticulum calcium ATPase inhibitor (c); and bisindolylmaleimide-I, a protein kinase C inhibitor (d). (e) Bar graph showing bradykinin-dependent response (the area between two facilitatory curves of EJPs in each graph from Figure 3, expressed as arbitrary units) in the presence of each inhibitor. ${ }^{*} P<0.05$ vs. control by two-way ANOVA. ${ }^{\dagger} P<0.05$ vs. no inhibitors by one-way ANOVA followed by Dunnett's multiple comparison test.

KCNQ channel modulators should be taken into account when their clinical use is considered.

Activation of phospholipase $\mathrm{C}$ yields inositol triphosphate and diacylglycerol. Inositol triphosphate induces $\mathrm{Ca}^{2+}$ release from the endoplasmic reticulum. It has been suggested that $\mathrm{Ca}^{2+}$ release from intracellular $\mathrm{Ca}^{2+}$ stores acts on KCNQ channels to activate or inhibit via phosphatidylinositol-4-kinase-dependent $\mathrm{PIP}_{2}$ synthesis or direct activation of calmodulin, respectively. ${ }^{45}$ Furthermore, it has been suggested that TRPA1 is also sensitized by bradykinin-induced release of $\mathrm{Ca}^{2+}$ from intracellular calcium stores. ${ }^{8}$ To evaluate the role of intracellular $\mathrm{Ca}^{2+}$ stores, cyclopiazonic acid was used in the present study. Pretreatment with cyclopiazonic acid did not alter the action of bradykinin in rat mesenteric arteries. In addition, the inhibition of protein kinase $\mathrm{C}$, which is activated by diacylglycerol, did not exhibit an effect. These findings suggest that the downstream metabolites of phospholipase $\mathrm{C}$ are not likely to be involved in bradykinin-induced facilitation of EJPs in our study.

In the presence of $\omega$-conotoxin GVIA $\left(10^{-6} \mathrm{moll}^{-1}\right)$, the amplitudes of EJPs were nearly abolished, and the enhancing effect of bradykinin could not be detected. A lower concentration of 
a

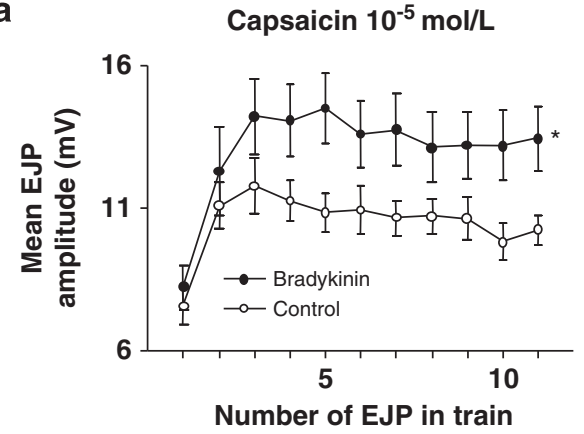

C

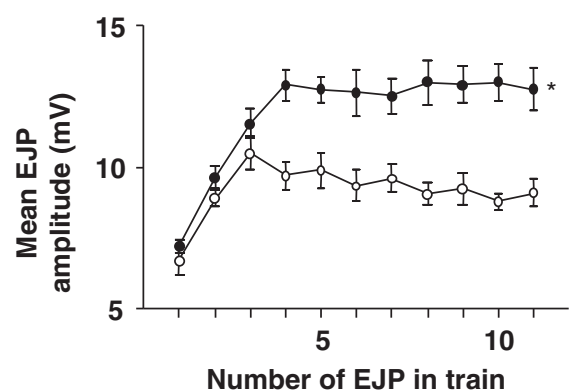

e
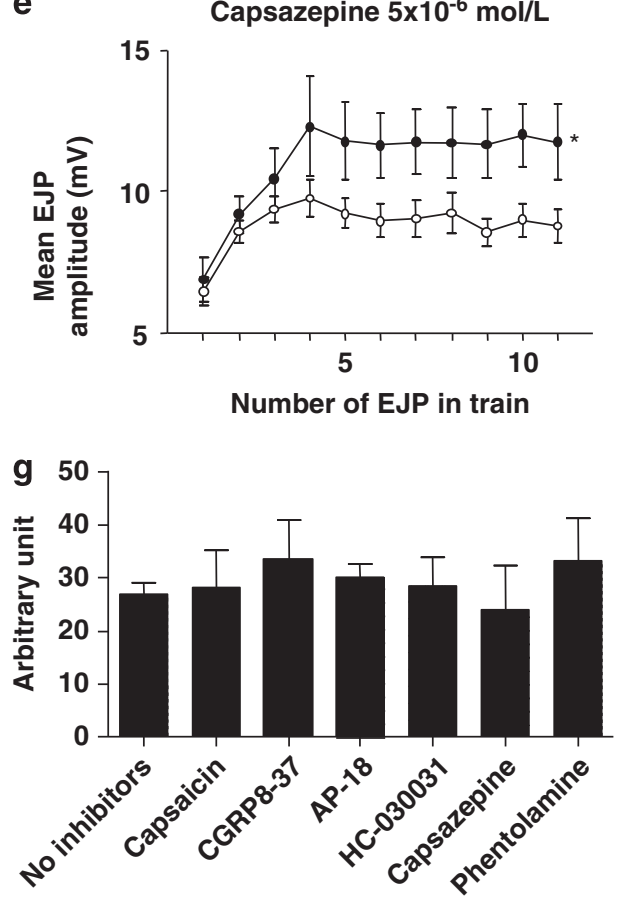

b CGRP8-37 $10^{-7} \mathrm{~mol} / \mathrm{L}$

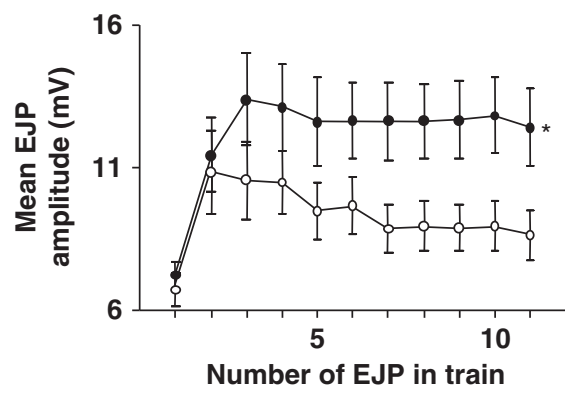

d

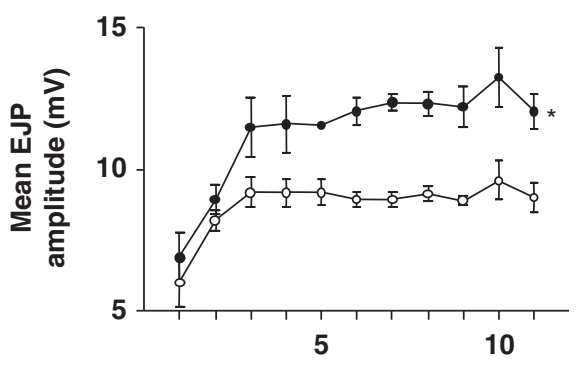

Number of EJP in train

f Phentolamine $10^{-4} \mathrm{~mol} / \mathrm{L}$

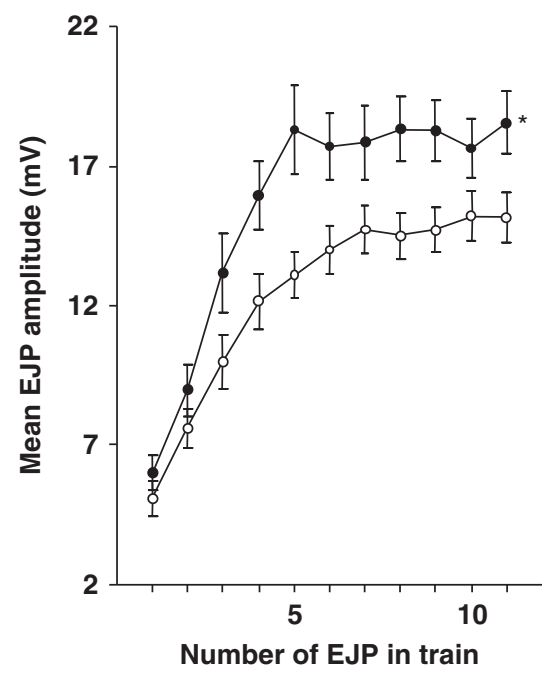

Figure 4 Line graphs showing the effects of $10^{-7}$ moll ${ }^{-1}$ bradykinin on EJPs in the rat mesenteric artery in the presence of the following: capsaicin, which desensitizes sensory nerves (a); CGRP8-37, a CGRP inhibitor (b); AP-18, a TRPA1 inhibitor (c); HC-030031, a TRPA1 inhibitor (d); capsazepine, a TRPV1 inhibitor (e); and phentolamine, an $\alpha$-adrenoceptor inhibitor (f). (g) Bar graph showing bradykinin-dependent response (the area between two facilitatory curves of EJPs in each graph from Figure 4 , expressed as arbitrary units) in the presence of each inhibitor. ${ }^{*}<0.05$ vs. control by two-way ANOVA.

$\omega$-conotoxin GVIA $\left(2 \times 10^{-9} \mathrm{moll}^{-1}\right)$ significantly, but mildly, decreased the amplitude of EJPs. Again, no enhancing effect of bradykinin was detected even under these conditions. Thus, calcium influx through N-type voltage-dependent calcium channels may have a crucial role in perivascular sympathetic nerve function, and KCNQ channels inhibited by bradykinin might contribute to the depolarization of presynaptic membrane potentials, which both activate $\mathrm{Ca}^{2+}$ influx through $\mathrm{N}$-type calcium channels and trigger exocytosis of neurotransmitters from sympathetic neurons. 
Transient receptor potential channels are non-selective cation channels and cause an influx of $\mathrm{Na}^{+}$and $\mathrm{Ca}^{2+}$ into the cell, resulting in neural excitation. It has been shown that protein kinase $\mathrm{C}$ and TRPV1 may contribute to sensory neuron excitation and sensitization by bradykinin. ${ }^{8,50}$ Furthermore, intracellular $\mathrm{Ca}^{2+}$ release has been demonstrated to be associated with sensitization of TRPA1. ${ }^{8}$ These transient receptor potential channels are mainly reported to work in sensory nerves; however, perivascular sympathetic nerves co-exist with sensory nerves. Thus, sensory nerves might modulate the function of sympathetic nerves. ${ }^{51}$ In the present study, inhibition of TRPA1 with AP-18 or HC-030031 did not alter the action of bradykinin. Furthermore, incubation with capsazepine, a TRPV1 antagonist, did not show any effect on the facilitatory action of bradykinin. Desensitization of sensory nerves with capsaicin was also without effect. These findings suggest that the facilitatory effect of bradykinin is independent of sensory nerves as well as TRPA1 and TRPV1.

One may argue that the concentration of bradykinin used in this study was relatively high. It is unclear whether the local concentration of bradykinin was high enough to cause an enhancement of sympathetic nerve activity. In our previous study, the enhancing effect of bradykinin was not statistically significant at $10^{-8} \mathrm{moll}^{-1}$, although $>10^{-7} \mathrm{moll}^{-1}$ bradykinin substantially increased the sympathetic neurotransmission in rat mesenteric arteries. ${ }^{3}$ In addition, several studies have demonstrated that the interstitial concentration of bradykinin ranges from approximately $10^{-11} \mathrm{moll}^{-1}$ to $10^{-7} \mathrm{moll}^{-1}$, and the concentration of bradykinin actually reaches approximately $10^{-7} \mathrm{moll}^{-1}$, the dose used in the present study, during exercise or ischemic preconditioning. ${ }^{52-54}$

The present study had several limitations. First, we did not evaluate the subtypes of KCNQ channels involved in the actions of bradykinin in perivascular sympathetic nerves because all types of KCNQ channels were shown to be inhibited by XE-991, an effective and relatively selective inhibitor of KCNQ channels at a concentration of $10^{-5} \mathrm{moll}^{-1} .^{55}$ Several studies have demonstrated that the M-current is associated with KCNQ3 and KCNQ4 channels in sympathetic neurons, ${ }^{9,17,56}$ but this has not been evaluated in perivascular sympathetic nerves. Further investigation would be needed to determine the involved subtypes of KCNQ channels in this study. Second, as mentioned above, the EJPs evaluated in this study reflect purinergic sympathetic neurotransmission, but they are not a direct measurement of neurotransmitter release; however, in a recently conducted study, it was demonstrated that the release of norepinephrine is facilitated by bradykinin in rat mesenteric arteries and veins. ${ }^{57}$ Third, little evidence is available concerning the effect of bradykinin on perivascular sympathetic neurotransmission, especially in humans. The effects of bradykinin on sympathetic nerves are likely to be highly species- and tissue-specific; ${ }^{57-60}$ thus, the relevance of the present findings to human arteries remains to be determined.

In conclusion, degradation of $\mathrm{PIP}_{2}$ by phospholipase $\mathrm{C}$ via presynaptic bradykinin $\mathrm{B}_{2}$ receptors enhances purinergic neurotransmission in rat mesenteric arteries. The inhibition of KCNQ channels following reduced $\mathrm{PIP}_{2}$ may be essential for the $\mathrm{PIP}_{2}$-dependent regulation of sympathetic neurotransmission. In addition, N-type calcium channels activated via membrane depolarization triggered by inhibited KCNQ channels may contribute to enhanced sympathetic neurotransmission.

\section{CONFLICT OF INTEREST}

The authors declare no conflicts of interest.
1 Morris JL, Gibbins IL, Kadowitz PJ, Herzog H, Kreulen DL, Toda N, Claing A. Roles of peptides and other substances in cotransmission from vascular autonomic and sensory neurons. Can J Physiol Pharmacol 1995; 73: 521-532.

2 Burnstock G. Local mechanisms of blood flow control by perivascular nerves and endothelium. J Hypertens 1990; 8(suppl 7): S95-106.

3 Kansui Y, Fujii K, Goto K, Abe I. Bradykinin enhances sympathetic neurotransmission in rat blood vessels. Hypertension 2002; 39: 29-34.

4 Ralevic V, Kendall DA. Cannabinoid modulation of perivascular sympathetic and sensory neurotransmission. Curr Vasc Pharmacol 2009; 7: 15-25.

5 Jadhav $\mathrm{V}$, Jabre $\mathrm{A}$, Chen MF, Lee TJ. Presynaptic prostaglandin E2 EP1-receptor facilitation of cerebral nitrergic neurogenic vasodilation. Stroke 2009; 40: 261-269.

6 Leeb-Lundberg LM, Marceau F, Muller-EsterI W, Pettibone DJ, Zuraw BL. International union of pharmacology. XLV. Classification of the kinin receptor family: from molecular mechanisms to pathophysiological consequences. Pharmacol Rev 2005; 57: 27-77.

7 Nakashima M, Mombouli JV, Taylor AA, Vanhoutte PM. Endothelium-dependent hyperpolarization caused by bradykinin in human coronary arteries. J Clin Invest 1993; 92: 2867-2871

8 Mizumura K, Sugiura T, Katanosaka K, Banik RK, Kozaki Y. Excitation and sensitization of nociceptors by bradykinin: what do we know? Exp Brain Res 2009; 196: 53-65.

9 Wang HS, Pan Z, Shi W, Brown BS, Wymore RS, Cohen IS, Dixon JE, McKinnon D. KCNQ2 and KCNQ3 potassium channel subunits: molecular correlates of the M-channel. Science 1998; 282: 1890-1893.

10 Roche JP, Westenbroek R, Sorom AJ, Hille B, Mackie K, Shapiro MS. Antibodies and a cysteine-modifying reagent show correspondence of $M$ current in neurons to KCNQ2 and KCNQ3 K+ channels. Br J Pharmacol 2002; 137: 1173-1186.

11 Cooper EC, Harrington E, Jan YN, Jan LY. M channel KCNQ2 subunits are localized to key sites for control of neuronal network oscillations and synchronization in mouse brain. J Neurosci 2001; 21: 9529-9540.

12 Lerche C, Scherer CR, Seebohm G, Derst C, Wei AD, Busch AE, Steinmeyer K. Molecular cloning and functional expression of KCNQ5, a potassium channel subunit that may contribute to neuronal M-current diversity. J Biol Chem 2000; 275: 22395-22400.

13 Marrion NV. Control of M-current. Annu Rev Physiol 1997; 59: 483-504.

14 Peters HC, Hu H, Pongs O, Storm JF, Isbrandt D. Conditional transgenic suppression of $M$ channels in mouse brain reveals functions in neuronal excitability, resonance and behavior. Nat Neurosci 2005; 8: 51-60.

15 Haley JE, Abogadie FC, Delmas P, Dayrell M, Vallis Y, Milligan G, Caulfield MP, Brown DA, Buckley NJ. The alpha subunit of Gq contributes to muscarinic inhibition of the M-type potassium current in sympathetic neurons. J Neurosci 1998; 18: 4521-4531.

16 Constanti A, Brown DA. M-Currents in voltage-clamped mammalian sympathetic neurones. Neurosci Lett 1981; 24: 289-294.

17 Shapiro MS, Roche JP, Kaftan EJ, Cruzblanca H, Mackie K, Hille B. Reconstitution of muscarinic modulation of the $\mathrm{KCNQ} 2 / \mathrm{KCNQ3} \mathrm{K}(+)$ channels that underlie the neuronal M current. J Neurosci 2000; 20: 1710-1721.

18 Jones S, Brown DA, Milligan G, Willer E, Buckley NJ, Caulfield MP. Bradykinin excites rat sympathetic neurons by inhibition of $M$ current through a mechanism involving $B 2$ receptors and G alpha q/11. Neuron 1995; 14: 399-405.

19 Onaka U, Fujii K, Abe I, Fujishima M. Enhancement by exogenous and locally generated angiotensin II of purinergic neurotransmission via angiotensin type 1 receptor in the guinea-pig isolated mesenteric artery. Br J Pharmacol 1997; 122: 942-948.

20 Kansui Y, Garland CJ, Dora KA. Enhanced spontaneous $\mathrm{Ca} 2+$ events in endothelial cells reflect signalling through myoendothelial gap junctions in pressurized mesenteric arteries. Cell Calcium 2008; 44: 135-146.

21 Fukao M, Hattori Y, Kanno M, Sakuma I, Kitabatake A. Sources of $\mathrm{Ca} 2+$ in relation to generation of acetylcholine-induced endothelium-dependent hyperpolarization in rat mesenteric artery. Br J Pharmacol 1997; 120: 1328-1334.

22 Earley S, Gonzales AL, Cmich R. Endothelium-dependent cerebral artery dilation mediated by TRPA1 and $\mathrm{Ca}^{+}{ }^{+}$-Activated $\mathrm{K}^{+}$channels. Circ Res 2009; 104: 987-994.

23 Kozaki Y, Kambe F, Hayashi Y, Ohmori S, Seo H, Kumazawa T, Mizumura K. Molecular cloning of prostaglandin EP3 receptors from canine sensory ganglia and their facilitatory action on bradykinin-induced mobilization of intracellular calcium. J Neurochem 2007; 100: 1636-1647.

24 Santini E, Porter JT. M-type potassium channels modulate the intrinsic excitability of infralimbic neurons and regulate fear expression and extinction. J Neurosci 2010; 30: 12379-12386.

25 Rodríguez-Rodríguez R, Yarova P, Winter P, Dora KA. Desensitization of endothelial $\mathrm{P} 2 \mathrm{Y} 1$ receptors by $\mathrm{PKC}$-dependent mechanisms in pressurized rat small mesenteric arteries. Br J Pharmacol 2009; 158: 1609-1620.

26 Buck SH, Burks TF. The neuropharmacology of capsaicin: review of some recent observations. Pharmacol Rev 1986; 38: 179-226.

27 Ahern GP, Brooks IM, Miyares RL, Wang XB. Extracellular cations sensitize and gate capsaicin receptor TRPV1 modulating pain signaling. J Neurosci 2005; 25: 5109-5116.

28 McPherson GA, Angus JA. Phentolamine and structurally related compounds selectively antagonize the vascular actions of the $\mathrm{K}^{+}$channel opener, cromromakalim. $\mathrm{Br} \mathrm{J}$ Pharmacol 1989; 97: 941-949.

29 Haddock RE, Hirst GD, Hill CE. Voltage independence of vasomotion in isolated irideal arterioles of the rat. J Physiol 2002; 540: 219-229. 
30 Pruneau D, Angus JA, Omega-conotoxin GVIA. is a potent inhibitor of sympathetic neurogenic responses in rat small mesenteric arteries. Br J Pharmacol 1990; 100: 180-184

31 Goto K, Fujii K, Onaka U, Abe I, Fujishima M. Effects of adrenomedullin and PAMP on membrane potential and neurotransmission. Peptides 2000; 21: 257-263.

32 Hashitani H, Windle A, Suzuki H. Neuroeffector transmission in arterioles of the guinea-pig choroid. J Physiol 1998; 510: 209-223.

33 Ford CP, Stemkowski PL, Light PE, Smith PA. Experiments to test the role of phosphatidylinositol 4,5-bisphosphate in neurotransmitter-induced M-channel closure in bullfrog sympathetic neurons. J Neurosci 2003; 23: 4931-4941.

34 Ro JY, Lee JS, Zhang Y. Activation of TRPV1 and TRPA1 leads to muscle nociception and mechanical hyperalgesia. Pain 2009; 144: 270-272.

35 von Kugelgen I, Starke K. Noradrenaline-ATP co-transmission in the sympathetic nervous system. Trends Pharmacol Sci 1991; 12: 319-324.

36 Donoso MV, Steiner M, Huidobro-Toro JP. BIBP 3226, suramin and prazosin identify neuropeptide $\mathrm{Y}$, adenosine $5^{\prime}$-triphosphate and noradrenaline as sympathetic cotransmitters in the rat arterial mesenteric bed. J Pharmacol Exp Ther 1997; 282: 691-698.

37 Driessen B, von Kugelgen I, Starke K. Neural ATP release and its alpha 2-adrenoceptormediated modulation in guinea-pig vas deferens. Naunyn Schmiedebergs Arch Pharmacol 1993; 348: 358-366.

38 Stjarne L, Stjarne E. Geometry, kinetics and plasticity of release and clearance of ATP and noradrenaline as sympathetic cotransmitters: roles for the neurogenic contraction. Prog Neurobiol 1995; 47: 45-94.

39 Prado GN, Taylor L, Zhou X, Ricupero D, Mierke DF, Polgar P. Mechanisms regulating the expression, self-maintenance, and signaling-function of the bradykinin B2 and B1 receptors. J Cell Physiol 2002; 193: 275-286.

40 Gutowski S, Smrcka A, Nowak L, Wu DG, Simon M, Sternweis PC. Antibodies to the alpha q subfamily of guanine nucleotide-binding regulatory protein alpha subunits attenuate activation of phosphatidylinositol 4,5-bisphosphate hydrolysis by hormones. J Biol Chem 1991; 266: 20519-20524.

41 LaMorte VJ, Harootunian AT, Spiegel AM, Tsien RY, Feramisco JR. Mediation of growth factor induced DNA synthesis and calcium mobilization by Gq and Gi2. J Cell Biol 1993; 121: 91-99.

42 Liebmann C, Graness A, Ludwig B, Adomeit A, Boehmer A, Boehmer FD, Nurnberg B Wetzker R. Dual bradykinin B2 receptor signalling in A431 human epidermoid carcinoma cells: activation of protein kinase $C$ is counteracted by a GS-mediated stimulation of the cyclic AMP pathway. Biochem J 1996; 313: 109-118.

43 Ewald DA, Pang IH, Sternweis PC, Miller RJ. Differential G protein-mediated coupling of neurotransmitter receptors to $\mathrm{Ca}^{2+}$ channels in rat dorsal root ganglion neurons in vitro. Neuron 1989; 2: 1185-1193.

44 Yanaga F, Hirata M, Koga T. Evidence for coupling of bradykinin receptors to a guaninenucleotide binding protein to stimulate arachidonate liberation in the osteoblast-like cell line, MC3T3-E1. Biochim Biophys Acta 1991; 1094: 139-146.

45 Brown DA, Hughes SA, Marsh SJ, Tinker A. Regulation of M(Kv7.2/7.3) channels in neurons by $\mathrm{PIP}(2)$ and products of $\mathrm{PIP}(2)$ hydrolysis: significance for receptormediated inhibition. J Physiol 2007; 582: 917-925.
46 Mackie AR, Brueggemann LI, Henderson KK, Shiels AJ, Cribbs LL, Scrogin KE, Byron $\mathrm{KL}$. Vascular KCNQ potassium channels as novel targets for the control of mesenteric artery constriction by vasopressin, based on studies in single cells, pressurized arteries, and in vivo measurements of mesenteric vascular resistance. $J$ Pharmacol Exp Ther 2008; 325: 475-483.

47 Ng FL, Davis AJ, Jepps TA, Harhun MI, Yeung SY, Wan A, Reddy M, Melville D, Nardi A Khong TK, Greenwood IA. Expression and function of the $\mathrm{K}^{+}$channel $\mathrm{KCNQ}$ genes in human arteries. Br J Pharmacol 2011; 162: 42-53.

48 Yeung SY, Pucovsky V, Moffatt JD, Saldanha L, Schwake M, Ohya S, Greenwood IA. Molecular expression and pharmacological identification of a role for $\mathrm{K}(\mathrm{v}) 7$ channels in murine vascular reactivity. Br J Pharmacol 2007; 151: 758-770.

49 Jepps TA, Chadha PS, Davis AJ, Harhun MI, Cockerill GW, Olesen SP, Hansen RS, Greenwood IA. Downregulation of Kv7.4 channel activity in primary and secondary hypertension. Circulation 2011; 124: 602-611.

50 Shin J, Cho H, Hwang SW, Jung J, Shin CY, Lee SY, Kim SH, Lee MG, Choi YH, Kim J, Haber NA, Reichling DB, Khasar S, Levin eJD Oh U.. Bradykinin-12-lipoxygenase-VR1 signaling pathway for inflammatory hyperalgesia. Proc Natl Acad Sci USA 2002; 99: $10150-10155$

51 Seyedi N, Maruyama R, Levi R. Bradykinin activates a cross-signaling pathway between sensory and adrenergic nerve endings in the heart: a novel mechanism of ischemic norepinephrine release? J Pharmacol Exp Ther 1999; 290: 656-663.

52 Langberg H, Bjorn C, Boushel R, Hellsten Y, Kjaer M. Exercise-induced increase in interstitial bradykinin and adenosine concentrations in skeletal muscle and peritendinous tissue in humans. J Physiol 2002; 542: 977-983.

53 Barlas A, Sugio K, Greenbaum LM. Release of T-kinin and bradykinin in carrageenin induced inflammation in the rat. FEBS Lett 1985; 190: 268-270.

54 Schulz R, Post H, Vahlhaus C, Heusch G. Ischemic preconditioning in pigs: a graded phenomenon: its relation to adenosine and bradykinin. Circulation 1998; 98: 1022-1029.

55 Wladyka CL, Kunze DL. KCNQ/M-currents contribute to the resting membrane potential in rat visceral sensory neurons. J Physiol 2006; 575: 175-189.

56 Hadley JK, Passmore GM, Tatulian L, AI-Qatari M, Ye F, Wickenden AD, Brown DA Stoichiometry of expressed KCNQ2/KCNQ3 potassium channels and subunit composition of native ganglionic $M$ channels deduced from block by tetraethylammonium J Neurosci 2003; 23: 5012-5019.

57 Talaia C, Morato M, Quintas C, Goncalves J, Queiroz G. Functional crosstalk of prejunctional receptors on the modulation of noradrenaline release in mesenteric vessels: A differential study of artery and vein. Eur J Pharmacol 2011; 652: 33-39.

58 Starke K, Peskar BA, Schumacher KA, Taube HD. Bradykinin and postganglionic sympathetic transmission. Naunyn Schmiedebergs Arch Pharmacol 1977; 299: 23-32.

59 Thapaliya S, Matsuyama H, El-Mahmoudy A, Shimizu Y, Takewaki T. An endotheliumderived factor modulates purinergic neurotransmission to mesenteric arterial smooth muscle of hamster. Eur J Pharmacol 2003; 461: 129-137.

60 Ronai AZ. Bradykinin and angiotensin II inhibit neurotransmission in rabbit ear artery by releasing prostanoids. Eur J Pharmacol 1991; 198: 93-95. 